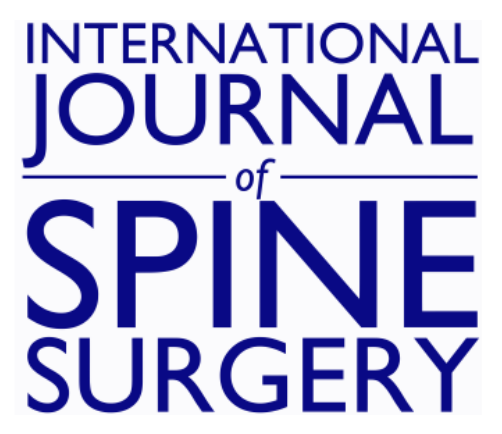

\title{
Preoperative and Postoperative Sagittal Alignment and Compensatory Mechanisms in Patients With Posttraumatic Thoracolumbar Deformities Who Undergo Corrective Surgeries
}

Oscar Bravo Olivares, Manuel Valencia Carrasco, Guillermo Izquierdo Pinto, Felipe Novoa Tonda, José Antonio Riera Martínez and Alvaro Silva González

Int J Spine Surg 2021, 15 (3) 585-590

doi: https://doi.org/10.14444/8079

http://ijssurgery.com/content/15/3/585

This information is current as of April 26, 2023.

Email Alerts Receive free email-alerts when new articles cite this article. Sign up at: http://ijssurgery.com/alerts 


\title{
Preoperative and Postoperative Sagittal Alignment and Compensatory Mechanisms in Patients With Posttraumatic Thoracolumbar Deformities Who Undergo Corrective Surgeries
}

\author{
OSCAR BRAVO OLIVARES, MD, ${ }^{1}$ MANUEL VALENCIA CARRASCO, $\mathrm{MD},{ }^{1,2}$ GUILLERMO IZQUIERDO \\ PINTO, MD ${ }^{1}$ FELIPE NOVOA TONDA, MD ${ }^{1,2}$ JOSÉ ANTONIO RIERA MARTÍNEZ, MD ${ }^{1}$ ALVARO SILVA \\ GONZÁLEZ, MD ${ }^{2}$ \\ ${ }^{I}$ Mutual de Seguridad, Spine Surgical Unit, Santiago, Chile ${ }^{2}$ Clinica Alemana - Universidad del Desarrollo, Santiago, Chile
}

\begin{abstract}
Background: Secondary posttraumatic spinal kyphosis is a fixed deformity that has an asymptomatic presentation in most patients, but in some, persistent pain and disability can develop refractory to conservative treatment, which may result in the need for corrective surgery. Our aim was to analyze the modification of sagittal alignment and the variation in compensation mechanisms of spinal-pelvic segments before and after surgical correction in a group of patients with symptomatic posttraumatic kyphosis.

Methods: A retrospective cohort study of 16 consecutive patients from the beginning of 2007 until the beginning of 2017 who underwent surgery due to thoracolumbar sagittal deformities was performed. Regional kyphosis (RK), thoracic kyphosis (TK), lumbar lordosis (LL), lower lumbar lordosis (LLL), lumbar lordosis under the deformity (LLUD), pelvic incidence (PI), pelvic tilt (PT), sagittal vertical axis (SVA), and PI-LL were measured in preoperative and postoperative lateral full spine $\mathrm{x}$ rays. Statistical analysis was performed with the nonparametric Wilcoxon test to compare preoperative and postoperative radiologic variables.

Results: Sixteen patients were included with a median age of 47.5 years (32-62 years), the median time elapsed from the accident until corrective surgery was 7 months (2-33 months), the median follow-up time was 16.5 months (680 months), and the most used corrective strategy was pedicle subtraction osteotomy (11/16 patients). Statistically and radiologically significant improvements were observed in RK $\left(33.5^{\circ}\right.$ versus $\left.12^{\circ}, P<.001\right)$ and LLUD $\left(68.5^{\circ}\right.$ versus $61^{\circ}$, $P=.017)$, with a noticeable decrease in PI-LL $\left(15^{\circ}\right.$ versus $\left.9.5^{\circ}, P=.233\right)$. There were no statistically significant results regarding TK, LL, LLL, PI, PT, or SVA.

Conclusions: Osteotomies are an effective tool to correct angular deformities at a local level after spine trauma. Posttraumatic kyphosis results in the compensation of sagittal imbalance through modification of segmental alignment of the mobile spine under the deformity.
\end{abstract}

Level of Evidence: 3.

Clinical Relevance: This work shows the compensation mechanisms after post-traumatic kyphosis in patients with previously healthy spines.

Other \& Special Categories

Keywords: posttraumatic deformity, compensatory mechanisms, sagittal imbalance

\section{BACKGROUND}

Posttraumatic spinal kyphosis is often a consequence of an untimely diagnosis or the inappropriate treatment of vertebral fractures. Although these deformities have an asymptomatic presentation in most patients, in some, the deformity may have clinical relevance due to pain, incapacity, and impaired quality of life, which may result in the need for corrective surgery.
Posttraumatic kyphosis is often a fixed deformity that habitually results in compensated misalignment, characterized by maintenance of the physiological mechanical axis due to compensatory mechanisms such as lumbar hyperlordosis and spinal dorsal hypokyphosis. ${ }^{1,2}$

Unlike kyphotic deformities caused by degenerative pathology in adults, who have poor bone quality and in whom correction is performed in the lower lumbar spine, posttraumatic deformities tend 
to present in young patients with no comorbidities and very good bone quality, in whom corrective osteotomies are performed at the same level as the deformity. ${ }^{3}$

Unlike the literature in older patients, there is little literature regarding these patients with posttraumatic deformities.

The objective of our study was to analyze the modification of sagittal alignment and the variation in compensation mechanisms of spinal-pelvic segments before and after surgical correction in a group of patients with symptomatic posttraumatic kyphosis.

\section{METHODS}

This was an observational, analytic, retrospective cohort study that included patients from the beginning of 2007 until the beginning of 2017.

The inclusion criteria were patients older than 18 years presenting with symptomatic posttraumatic kyphosis in thoracolumbar segments that prompted surgical correction and who had undergone at least 1 postsurgical follow-up period of 6 months or more. The exclusion criteria included incomplete or poor quality clinical and radiological records, which could hinder radiologic measurements.

Data were collected from the electronic records of each patient. The following variables were recorded: age, sex, trauma mechanism, fracture type, neurological state, initial treatment, time elapsed between fracture and surgery, osteotomy spinal level, and surgical correction type.

Preoperative and postoperative lateral full spine $\mathrm{x}$ rays were measured using the program Impax Results Viewer (AGFA HealthCare N.V., Belgium), which registered the following: regional kyphosis (RK) from the superior vertebral endplate of the cranial vertebra to the inferior vertebral endplate of the caudal vertebra adjacent to the fractured vertebra; thoracic kyphosis (TK) from T4 to T12; lumbar lordosis (LL) from L1 to S1; lower lumbar lordosis (LLL) of the superior vertebral endplate from L4 to the superior vertebral endplate of S1; lumbar lordosis under the deformity (LLUD) from the superior vertebral endplate of the caudal vertebra adjacent to the fractured vertebra to the superior vertebral endplate of $\mathrm{S} 1$ in preoperative images and from the superior vertebral endplate of the caudal vertebra adjacent to the instrumentation to the superior vertebral endplate of S1 in postop-

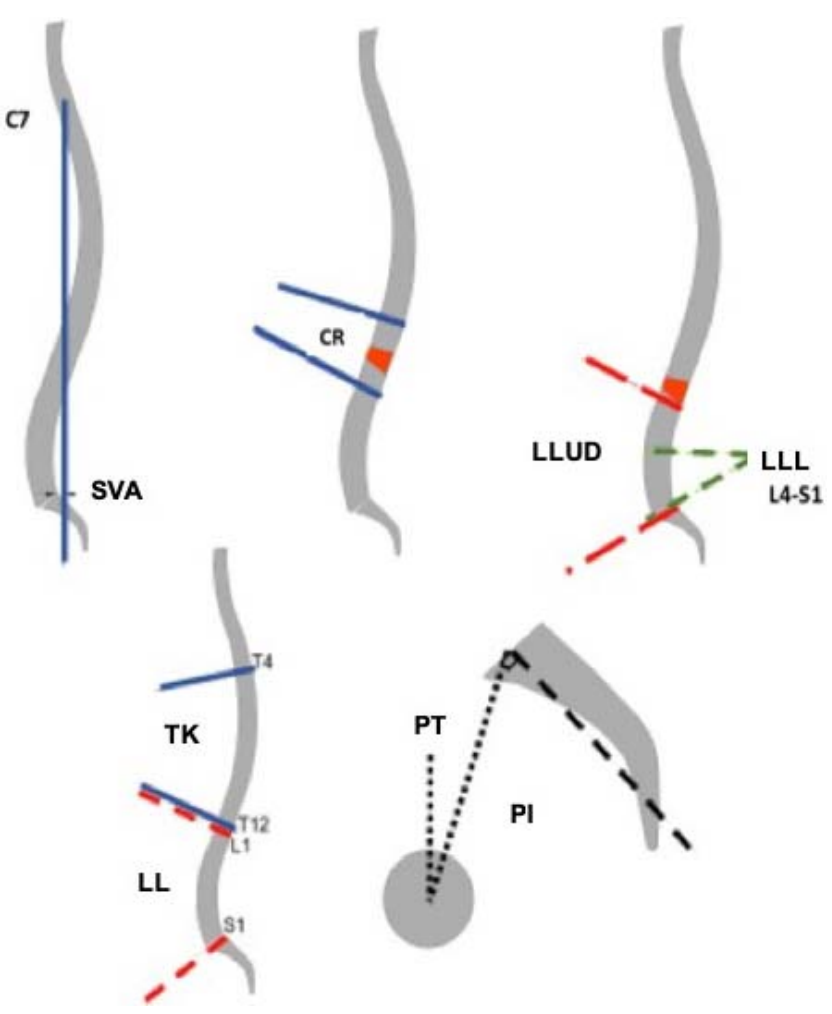

Figure 1. The spinopelvic parameters measured in our study.

erative images; pelvic incidence (PI); pelvic tilt (PT); sagittal vertical axis (SVA); and PI-LL (Figure 1).

Descriptions of the data were made for the central tendency and dispersion of each variable by a statistician. Statistical analysis was performed with the nonparametric Wilcoxon test to compare preoperative and postoperative radiologic variables. The analysis was performed using the program StataSE 14.0 (StataCorp, College Station, TX).

The research protocol was approved by the institutional ethics committee.

\section{RESULTS}

During the study period, 16 patients underwent operations: 14 men $(87.5 \%)$ and 2 women, with a median age of 47.5 years (32-62 years).

A total of $100 \%$ of the patients suffered from high-energy trauma, with $56.3 \%$ due to traffic accidents.

Eleven fractures were type A, and 5 were type B according to the AO classification. A total of $75 \%$ $(12 / 16)$ of patients were initially managed conservatively, and the deformity progressed due to failure of the anterior column. The other 4 patients previously underwent operations but progressed to postsurgical kyphosis due to vertebral collapse, 


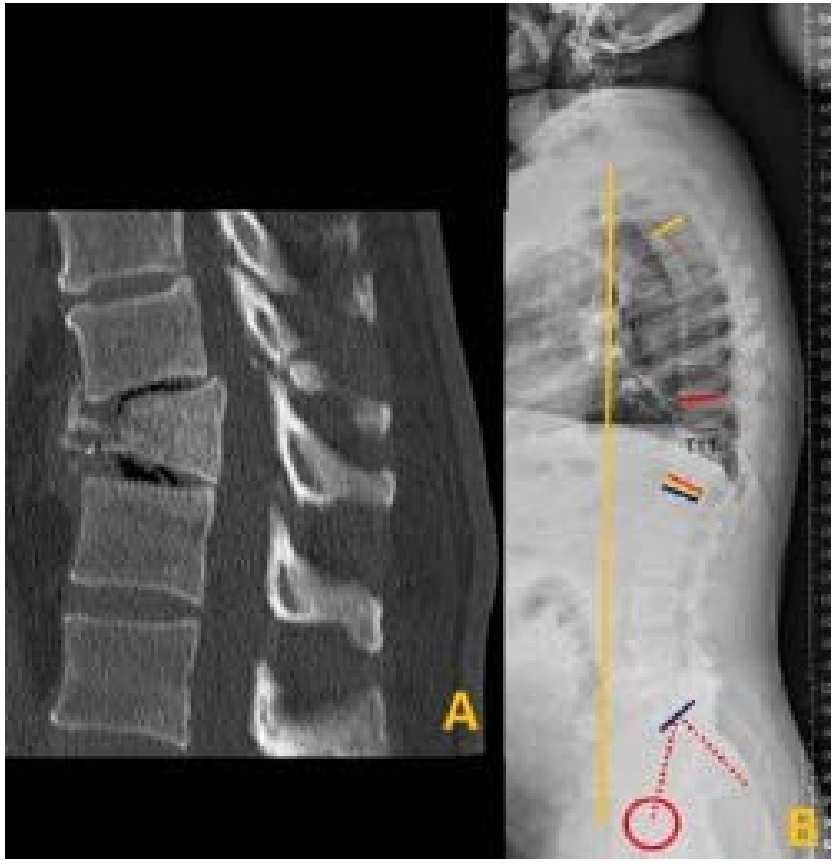

Figure 2. The case of a patient who had a car accident, which resulted in a misdiagnosed type $B$ fracture that progressed to a fixed kyphosis. (A) Computed tomography showing the kyphotic deformity. (B) Lateral full spine $x$ ray showing an unbalanced spine with $\mathrm{a}+61 \mathrm{~mm}$ sagittal vertical axis.

posterior ligament apparatus failure, or implant loosening (Figure 2).

The median time elapsed from the accident until corrective surgery was 7 months (2-33 months).

The most frequently operated levels were T12 and L1 $(62.5 \%)$, and the most used corrective strategy was pedicle subtraction osteotomy $(11 / 16)$. There were 3 vertebrectomies and 2 discovertebral osteotomies with intersomatic fusion performed, 1 of which was associated with a Smith-Petersen osteotomy (Table 1).

Regarding the radiologic parameters (Table 2), preoperative RK was $33.5^{\circ}$, and postcorrection RK was $12^{\circ}(P<.001)$; furthermore, preoperative LLUD was $68.5^{\circ}$, and postcorrection LLUD was $61^{\circ}(P=.017)$. There were no statistically significant results regarding TK, LL, LLL, PI, PT, or SVA; however, there was a noticeable decrease in PI-LL from $15^{\circ}$ preoperatively to $9.5^{\circ}$ postoperatively $(P=$ $.233)$.

\section{DISCUSSION}

Over the last few decades, the importance of sagittal alignment has been strongly emphasized as well as the relevance of pelvic parameters and the clinical repercussions of spinal imbalance. ${ }^{4-9}$ Most studies allude to imbalance in elderly patients with
Table 1. Preoperative and intraoperative variables.

\begin{tabular}{|c|c|}
\hline Variables & $\begin{array}{c}\text { Value, } \\
\mathrm{N}=16 \text { patients }\end{array}$ \\
\hline \multicolumn{2}{|l|}{ Sex } \\
\hline Male & 14 \\
\hline Female & 2 \\
\hline Age, median (range), y & $47.5(32-62)$ \\
\hline \multicolumn{2}{|l|}{ Type of accident } \\
\hline High energy & 16 \\
\hline Low energy & 0 \\
\hline \multicolumn{2}{|l|}{ Type of fracture } \\
\hline A & 11 \\
\hline $\mathrm{B}$ & 5 \\
\hline $\mathrm{C}$ & 0 \\
\hline \multicolumn{2}{|l|}{ Treatment before corrective surgery } \\
\hline Conservative & 12 \\
\hline Surgical & 4 \\
\hline Time accident-corrective surgery, median (range), mo & $7(2-33)$ \\
\hline \multicolumn{2}{|l|}{ Level of osteotomy } \\
\hline $\mathrm{T} 11$ & 3 \\
\hline T12 & 5 \\
\hline L1 & 5 \\
\hline L2 & 3 \\
\hline \multicolumn{2}{|l|}{ Type of osteotomy } \\
\hline OSP & 11 \\
\hline Anterior realignment & 5 \\
\hline Follow-up, median (range), mo & $16.5(6-80)$ \\
\hline
\end{tabular}

Abbreviation: OSP, pedicle subtraction osteotomy.

degenerative changes and significant comorbidities. ${ }^{7,9-11}$ Few studies have addressed posttraumatic kyphosis and the subsequent spinal imbalance.

Our group of patients was younger than those included in most papers published regarding degenerative deformities, in which the average age tended to be older than 70 years.

The high-energy injury mechanism and the thoracolumbar location of fractures have been habitually described for these types of acute and subacute kyphotic deformities.

Although the objective of this study was not to identify the causes leading to thoracolumbar kyphosis, we can mention that most cases were caused by failure of the anterior column or loss of surgical correction due to collapse and loosening of the implants; additionally, the time of surgery from 2 to 33 months was due to a combination of kyphotic angulation and painful lumbar symptoms that were intolerable by the patients.

Posttraumatic deformities are fixed or rigid deformities of a short segment of the spine. Pedicle subtraction osteotomy has significant corrective power and requires a single posterior approach. Osteotomy is the most recommended and used procedure in the literature. ${ }^{3,12-15}$ Coinciding with these observations, pedicle subtraction osteotomy was the most used method in our study group (11 out of 16 patients). Together with the results of 5 
Table 2. Preoperative and postoperative radiologic parameters.

\begin{tabular}{|c|c|c|c|}
\hline & Preoperative & Postoperative & $P^{\mathrm{a}}$ \\
\hline $\mathrm{CR}$, median (interquartile range), ${ }^{\circ}$ & $33.5(7.5)$ & $12(13.5)$ & $<.001$ \\
\hline LL, median (interquartile range), ${ }^{\circ}$ & $67(24)$ & $61(11.75)$ & .193 \\
\hline $\mathrm{CT}$, median (interquartile range), ${ }^{\circ}$ & $46(22)$ & $43.5(4.75)$ & .836 \\
\hline IP, median (interquartile range), ${ }^{\circ}$ & $56.5(9.75)$ & $55(4.75)$ & .762 \\
\hline PT, median (interquartile range), ${ }^{\circ}$ & $14.5(11.25)$ & $14.5(8.25)$ & .706 \\
\hline LLB, median (interquartile range), ${ }^{\circ}$ & $48(6)$ & $43.5(11.25)$ & .334 \\
\hline LLBD, median (interquartile range), ${ }^{\circ}$ & $68.5(6.5)$ & $61(8.5)$ & .017 \\
\hline IP-LL, median (interquartile range), ${ }^{\circ}$ & $15(14.25)$ & $9.5(7.25)$ & .233 \\
\hline LPC7, median (interquartile range), $\mathrm{mm}$ & $22(33)$ & $16.5(27.25)$ & .571 \\
\hline
\end{tabular}

Abbreviations: CR, text; CT, text; IP, text; IP-LL, text; LL, lumbar lordosis; LLB, text; LLBD, text; LPC7, text; PT, pelvic tilt.

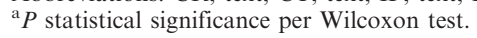

patients in whom a double corrective approach was used, the median difference in the correction of RK was significant $\left(21.5^{\circ}\right)$ between preoperative and postoperative values. In our group, global balance was maintained as measured by SVA in 13 out of 16 patients, and in 2 patients demonstrating negative imbalance, global balance was restored. Altogether, these corrective techniques had a success rate of $93.75 \%$ (correction range between $-3^{\circ}$ and $44^{\circ}$ ) in terms of the level of kyphotic deformity in our group, and they maintained and/or restored global sagittal balance, agreeing with what has been described in the literature ${ }^{16}$; additionally, despite demonstrating a higher risk of major complications, ${ }^{17-19}$ particularly neurological complications, due to the location being at the same level of the conus medullaris, ${ }^{20}$ these osteotomies at the level of the deformity achieved effective correction and better restored the original shape of the spine. In a series by $\mathrm{Kim}$ et $\mathrm{al}^{21}$ of 140 patients with fixed sagittal deformities due to multiple etiologies who underwent pedicle subtraction osteotomies, 17 presented with posttraumatic deformities (average age 62.3 years); a segmental correction of $37.6 \pm 4^{\circ}$ was reported in this subgroup, and a correction of $86 \mathrm{~mm}$ in SVA and $34.8^{\circ}$ in LL was reported in the whole series. In a series by Gao et $\mathrm{al}^{22}$ of 89 patients with posttraumatic deformities and an average age of 46.9 years, 42 underwent discovertebral osteotomy, and 44 underwent pedicle subtraction osteotomy and obtained similar clinical and radiologic results with a correction of the regional deformity from $39.6^{\circ} \pm 3.9^{\circ}$ to $5.6^{\circ} \pm 3.7^{\circ}$ in the discovertebral osteotomy group and from $39.1^{\circ} \pm 3.8^{\circ}$ to $4.8^{\circ} \pm$ $4.2^{\circ}$ in the pedicle subtraction group. Finally, Zeng et $\mathrm{al}^{23}$ in a series of 34 patients with an average age of 48.9 years who underwent a posterior approach and posterior osteotomy, reported a decrease in the regional deformity from $32.3^{\circ}$ to $0.9^{\circ}$ in the deformity group with less than or equal to $45^{\circ}$ of kyphosis and from $61.3^{\circ}$ to $12.3^{\circ}$ in the group with more than $45^{\circ}$ of kyphosis.

Unlike elderly patients with imbalance due to degenerative pathology, where compensation mechanisms such as pelvic retroversion and flexion of the lower extremities predominate, in young patients with posttraumatic thoracolumbar kyphosis, the reported compensation mechanisms are spinal hypokyphosis and lumbar hyperlordosis.,11,24 In our cohort, we found no differences in spinal kyphosis, but there was a significant reduction in lumbar lordosis under the deformity with conservation of the lumbopelvic parameters and SVA. This can probably be explained by the fact that young patients have a healthy and flexible spine that allows them to rebalance before changing the position of the pelvis; in fact, these flexible spines may even demonstrate overcorrection of hyperlordosis and may generate negative sagittal balance and overload of the lumbar facet joints. This fact may be a probable cause of the back pain observed in 2 patients in this study (Figure 3).

The main limitation of our work is its retrospective nature, which significantly restricted the inclusion of patients in the study due to the lack of comprehensive clinical and imaging records. This generated a limited number of patients, which affected the power of our results, as some of the results, such as LL and LLL, reached radiologically significant corrections (difference in medians of $6^{\circ}$ and $4.5^{\circ}$, respectively) but no statistical significance, which reinforces the idea that, in young patients with rigid thoracolumbar deformities, the main compensating mechanism is at the lumbar level.

\section{CONCLUSIONS}

Posttraumatic kyphosis results in the compensation of sagittal imbalance through the modification of segmental alignment of the mobile spine under 


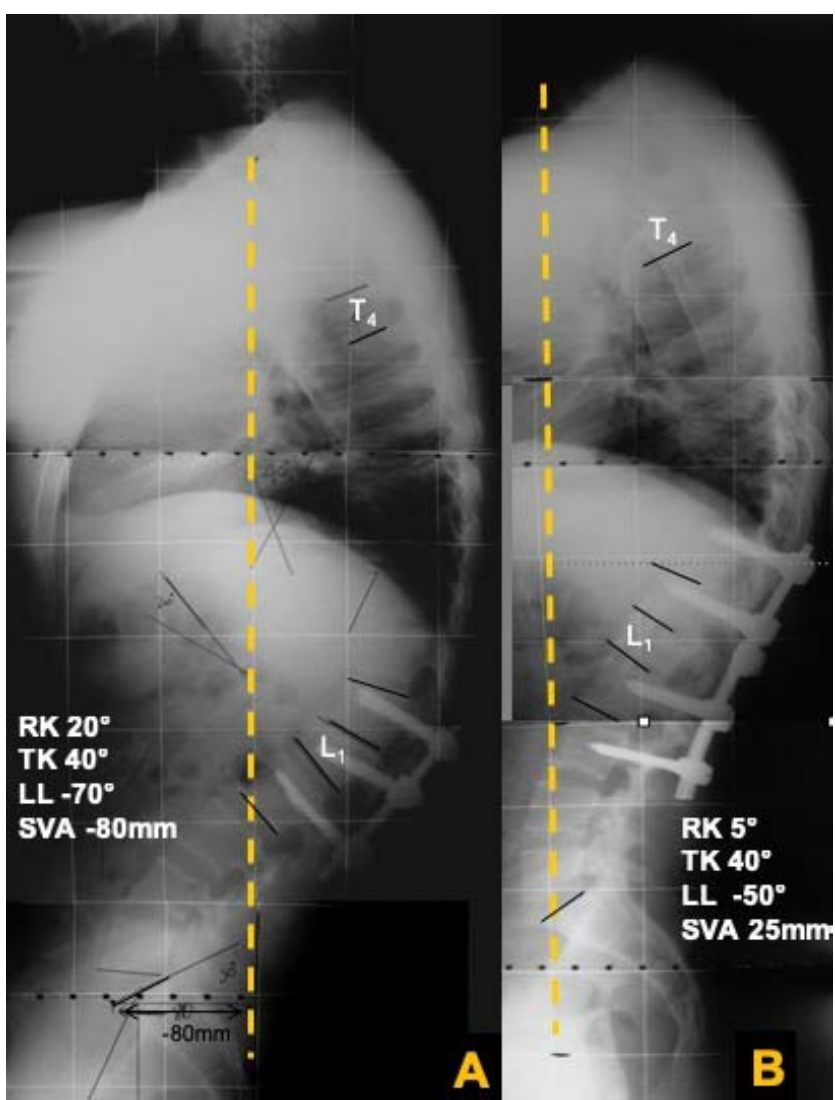

Figure 3. The case of a burst fracture initially treated with in situ fixation that evolved to local kyphosis. (A) Lateral full spine $x$ ray before the correction of kyphosis; we observed severe negative imbalance (sagittal vertical axis [SVA] $-80 \mathrm{~mm}$, regional kyphosis $[\mathrm{RK}] 20^{\circ}$, and lumbar lordosis [LL] $\left.-70^{\circ}\right)$. (B) Lateral full spine $x$ ray after the correction of kyphosis, showing normalization of the spinal parameters (SVA $+25 \mathrm{~mm}, \mathrm{RK} 5^{\circ}$, and $\mathrm{LL}-50^{\circ}$ ).

the deformity. Other compensatory mechanisms, such as pelvic retroversion, do not seem to be involved.

Osteotomies are an effective tool to correct angular deformities at a local level after spine trauma.

\section{REFERENCES}

1. Roussouly P, Pinheiro-Franco J. Biomechanical analysis of the spino-pelvic organization and adaptation in pathology. Eur Spine J. 2011;20(suppl 5):S609-S618. doi:10.1007/s00586011-1928-x

2. Lamartina C, Berjano P. Classification of sagittal imbalance based on spinal alignment and compensatory mechanisms. Eur Spine J. 2014;236):1177-1189. doi:10.1007/ s00586-014-3227-9

3. Vaccaro A, Silber J. Post-traumatic spinal deformity. Spine (Phila Pa 1976). 2001;26(24):S111-S118. doi:10.1097/ 00007632-200112151-00019

4. Dubousset J. Three-dimensional analysis of the scoliotic deformity. In: Weinstein S, editor. Pediatric Spine: Principles and Practice. New York: Raven Press; 1994:479-496.

5. Legaye J, Duval-Beaupère G, Hecquet J, Marty C. Pelvic incidence: a fundamental pelvic parameter for three-dimensional regulation of spinal sagittal curves. Eur Spine J. 1998;7(2):99103. doi:10.1007/s005860050038

6. Lafage V, Schwab F, Patel A, Hawkinson N, Farcy JP. Pelvic tilt and truncal inclination: two key radiographic parameters in the setting of adults with spinal deformity. Spine (Phila Pa 1976). 2009;34(17): 599-606. doi:10.1097/BRS. 0b013e3181aad219

7. Glassman S, Bridwell K, Dimar JR, Horton W, Berven S, Schwab F. The impact of positive sagittal balance in adult spinal deformity. Spine (Phila Pa 1976). 2005;30(18):20242029. doi:10.1097/01.brs.0000179086.30449.96

8. Schwab F, Patel A, Ungar B, Farcy JP, Lafage V. Adult spinal deformity-postoperative standing imbalance: how much can you tolerate? An overview of key parameters in assessing alignment and planning corrective surgery. Spine (Phila $\mathrm{Pa}$ 1976). 2010;35(25):2224-2231. doi:10.1097/BRS. 0b013e3181ee6bd4

9. Schwab F, Blondel B, Bess S, et al. Radiographic spinopelvic parameters and disability in the setting of adult spinal deformity: a prospective multicenter analysis. Spine (Phila Pa 1976). 2013;38(13):803-812. doi:10.1097/BRS. 0b013e318292b7b9

10. Savage J, Patel A. Fixed sagittal plane imbalance. Global Spine J. 2014;4:287-296. doi:10.1055/s-0034-1394126

11. Diebo B, Ferrero E, Lafage R, et al. Recruitment of compensatory mechanisms in sagittal spinal malalignment is age and regional deformity dependent: a full-standing axis analysis of key radiographical parameters. Spine (Phila Pa 1976). 2015;40:642-649. doi:10.1097/BRS.0000000000000844

12. Munting E. Surgical treatment of post-traumatic kyphosis in the thoracolumbar spine: indications and technical aspects. Eur Spine J. 2010;19(suppl 1):S69-S73. doi:10.1007/ s00586-009-1117-3

13. Bridwell K. Decision making regarding Smith-Petersen vs. pedicle subtraction osteotomy vs. vertebral column resection for spinal deformity. Spine (Phila Pa 1976). 2006;31:S171S178. doi:10.1097/01.brs.0000231963.72810.38

14. Buchowski J, Kuhns CA, Bridwell K, Lenke L. Surgical management of posttraumatic thoracolumbar kyphosis. Spine J. 2008;8(4):666-677. doi:10.1016/j.spinee.2007.03.006

15. Heary R, Bono C. Pedicle subtraction osteotomy in the treatment of chronic, posttraumatic kyphotic deformity. $J$ Neurosurg Spine. 2006;5:1-8. doi:10.3171/spi.2006.5.1.1

16. Kose K, Bozduman O, Yenigul A, Igrek S. Spinal osteotomies: indications, limits and pitfalls. EFORT Open Rev. 2017;2:73-82. doi:10.1302/2058-5241.2.160069

17. Smith J, Sansur C, Donaldson W, et al. Short-term morbidity and mortality associated with correction of thoracolumbar fixed sagittal plane deformity: a report from the Scoliosis Research Society Morbidity and Mortality Committee. Spine (Phila Pa 1976). 2011;36(12):958-64. doi:10.1097/ BRS.0b013e3181eabb26

18. Smith J, Klineberg E, Lafage V, et al. Prospective multicenter assessment of perioperative and minimum 2-year postoperative complication rates associated with adult spinal deformity surgery. J Neurosurg Spine. 2016;25(1):1-14. doi:10. 3171/2015.11.SPINE151036

19. Bridwell K, Lewis S, Edwards C, et al. Complications and outcomes of pedicle subtraction osteotomies for fixed sagittal imbalance. Spine (Phila Pa 1976). 2003;28(18):2093101. doi:10.1097/01.BRS.0000090891.60232.70 
20. Buchowski J, Bridwell K, Lenke L, et al. Neurologic complications of lumbar pedicle subtraction osteotomy: a 10year assessment. Spine (Phila Pa 1976). 2007;32(20):2245-2252. doi:10.1097/BRS.0b013e31814b2d52

21. Kim K, Lee S, Suk K, Lee J, Jeong B. Outcome of pedicle subtraction osteotomies for fixed sagittal imbalance of multiple etiologies: a retrospective review of 140 patients. Spine (Phila Pa 1976). 2012;37(19):1667-1675. doi:10.1097/BRS. 0b013e3182552fd0

22. Gao R, Wu J, Yuan W, Yang C, Pan F, Zhou X. Modified partial pedicle subtraction osteotomy for the correction of post-traumatic thoracolumbar kyphosis. Spine $J$. 2015;15(9):2009-2015. doi:10.1016/j.spinee.2015.04.047

23. Zeng Y, Chen Z, Sun C, et al. Posterior surgical correction of posttraumatic kyphosis of the thoracolumbar segment. J Spinal Disord Tech. 2013;26:37-41. doi:10.1097/ BSD.0b013e318231d6a3

24. Barrey C, Roussouly P, Perrin G, Le Huec J. Sagittal balance disorders in severe degenerative spine. Can we identify the compensatory mechanisms? Eur Spine J. 2011;20(suppl 5):626-633. doi:10.1007/s00586-011-1930-3

Disclosures and COl: The views expressed in the submitted article are our own and not an official position of the involved institutions. We did not use grants, equipment, drugs, and/or any other support that facilitated conducting the work described in the article or the writing of the article itself. Dr. Silva is a Medtronic speaker with personal fees. The rest of the authors declare no conflicts of interest. The research protocol was approved by the institutional ethics committee.

Corresponding Author: Alvaro Silva González, MD, Clinica Alemana - Universidad del Desarrollo, Spine Surgical Unit, Av. Manquehue Norte 1499, Santiago, Chile. Phone: (+56) 9 75280579; Email: alvarosilva@me.com.

Published 1 June 2021

This manuscript is generously published free of charge by ISASS, the International Society for the Advancement of Spine Surgery. Copyright $\odot 2021$ ISASS. To see more or order reprints or permissions, see http://ijssurgery.com. 